\title{
Laboratory Animal Shared Resource
}

National Cancer Institute

\section{Source}

National Cancer Institute. Laboratory Animal Shared Resource. NCI Thesaurus. Code C39444.

The Laboratory Animal Shared Resource is responsible for the supply, use, husbandry, and experimental model selection and development of laboratory animals utilized by the research programs at Cancer Center. The resource provides direction on appropriate techniques, strains or animal models to use in research protocols, maintains a pathogenfree environment, health surveillance, quarantine, full-panel testing and genetic monitoring for experimental animals. 